DOI: http://dx.doi.org/10.18203/2320-1770.ijrcog20194862

\title{
Fetal transverse cerebellar diameter measurement in intrauterine growth restriction: a more accurate parameter for gestational age assessment at term
}

\author{
Saroj Mourya $^{1}$, Harish Kumar Mourya ${ }^{2 *}$, Vimla Jain ${ }^{3}$, Manoj Verma ${ }^{4}$
}

\author{
${ }^{1}$ Department of Obstetrics and Gynecology, Dr. S. N. Medical College, Jodhpur, Rajasthan, India \\ ${ }^{2}$ Department of Pediatrics, Dr. S. N. Medical College, Jodhpur, Rajasthan, India \\ ${ }^{3}$ Department of Obstetrics and Gynecology, SMS Medical College, Jaipur, Rajasthan, India \\ ${ }^{4}$ Department of PSM, Dr. S. N. Medical College, Jodhpur, Rajasthan, India
}

Received: 06 September 2019

Accepted: 04 October 2019

\author{
*Correspondence: \\ Dr. Harish Kumar Mourya, \\ E-mail: harishmourya1@gmail.com
}

Copyright: () the author(s), publisher and licensee Medip Academy. This is an open-access article distributed under the terms of the Creative Commons Attribution Non-Commercial License, which permits unrestricted non-commercial use, distribution, and reproduction in any medium, provided the original work is properly cited.

\begin{abstract}
Background: Assessment of fetal gestational age (GA) is an essential part of obstetric USG. Accurate knowledge of fetal GA is important to facilitate the best possible prenatal care and successful pregnancy outcome. For the estimation of GA the commonly used parameters in third trimester are:- BPD, HC, AC and FL. As all these parameters are affected by fetal growth disorders and fetal position. TCD can be used as another parameter for the estimation of GA in growth restricted fetuses.

Methods: This study was conducted at Mahila Chikitsalaya Sanganeri Gate; SMS Medical College Jaipur from July 2005 to September 2006. A total of 80 pregnant women in third trimester with singleton pregnancy including 40 pregnant women with known cases of IUGR and 40 AGA fetuses were studied for TCD measure.

Results: Correlation coefficient between TCD and gestational age was highly significant and no significant difference was found in TCD of AGA and IUGR fetuses.

Conclusions: TCD measurement can be used as more reliable parameter for accurate estimation of gestational age in IUGR fetuses in third trimester.
\end{abstract}

Keywords: Appropriate for the gestational age, Gestational age, Intrauterine growth restriction, Third trimester pregnancy, Transverse cerebellar diameter, Ultrasonography

\section{INTRODUCTION}

Assessment of fetal gestational age (GA) is an essential part of obstetric ultrasonography (USG). Accurate knowledge of fetal GA is important to facilitate the best possible prenatal care and successful pregnancy outcome. A study by Pinar et al, found that inadequate assessment of gestational age at later stages of pregnancy and an inability to determine fetal GA in the presence of IUGR may be the result of not using the correct parameters. ${ }^{1}$ For the estimation of GA the commonly used parameters in third trimester are; Bi Parietal Diameter (BPD), head circumference, abdominal circumference and femur length.

As all these parameters are affected by fetal growth disorders and fetal position, Trans cerebellar diameter (TCD) can be used as a useful parameter for the estimation of GA in growth restricted fetuses. Fetal cerebellum starts developing at 5th week of antenatal life, continuous to develop throughout gestational period. The maximum diameter of this organ being transverse can be measured by USG accurately at all the stages of development. It is less vulnerable for deformation from extrinsic compression as it is located in thick bony fossa. 
It is not influenced by alteration in the fetal growth such as macrosomia and IUGR. ${ }^{2}$ TCD is emerging as a new sonographic parameter and is claimed to be more accurate in certain situations like extremes of growth abnormalities and variations of fetal head shape such as dolicocephaly and brachycephaly. ${ }^{3}$

Present study was conducted with the aim to assess TCD as predictor for GA assessment in IUGR fetuses in third trimester. The objective of the study was to determine correlation between gestational age and TCD to determine any difference in TCD between normal and IUGR fetus at different gestational age.

\section{METHODS}

This cross-sectional analytical study was conducted at Mahila Chikitsalaya Sanganeri Gate; SMS Medical College, Jaipur, a large tertiary care referral centre, over a period of one year from July 2005 to September 2006. A total of 80 pregnant women in third trimester with singleton pregnancy including 40 pregnant women with known cases of IUGR and 40 Adequate for gestational age fetuses were studied for TCD measurement.

Period of gestation was determined by last menstrual period ((LMP). A discrepancy of 4 weeks in period of gestation and clinical examination was taken as evidence of IUGR. Multiple gestation, polyhydramnios, transverse lie, oblique lie and mistaken / unsure date were excluded from the study. In all cases fundal height was measured in centimeters after that all patients underwent ultrasonography.

USG scan was done in both the groups in third trimester between 32-40 weeks of gestation with sure date of LMP. TCD was measured along with other traditional parameters for GA estimation. Fetal cerebellum was identified in the transverse view of posterior cranial fossa by using thalami, cavum septum pellucidum, followed by rotation of the transducer below the thalamic plane to view the butterfly like structure the cerebellum.

The TCD was measured in $\mathrm{mm}$ from outer to outer margin in widest transverse diameter. Actual gestational age was confirmed by post-natal new born assessment with expanded new Ballard score. Ethical clearance was obtained from Institute's Ethical committee prior to initiation of study and written informed consent was obtained from all subjects prior to data collection.

\section{Statistical analysis}

Continuous variables were summarized as mean and standard deviation was analyzed using t test. Correlation between two variables was determined using Pearson correlation co efficient. A p value less than 0.05 were taken as statistically significant. All analysis was carried out by using Epi info version 7.2.1.0 statistical software.

\section{RESULTS}

A total of 40 appropriate for gestational age and 40 IUGR cases were included in study. TCD in mm was measured by USG in all case along with other parameters. Strong positive correlation was found between TCD and Gestation age in both Normal and IUGR subjects with similar correlation coefficient at $\mathrm{p}<0.001$ (Table 1 ).

Table 1: Correlation between TCD and gestational age in normal and IUGR subjects.

\begin{tabular}{|lll|}
\hline & Normal & IUGR \\
\hline Correlation coefficient (r) & 0.647 & 0.766 \\
\hline P value & $<0.001(\mathrm{~S})$ & $<0.001(\mathrm{~S})$ \\
\hline
\end{tabular}

TCD: Trans-cerebellar diameter; IUGR: Intra uterine growth retardation.

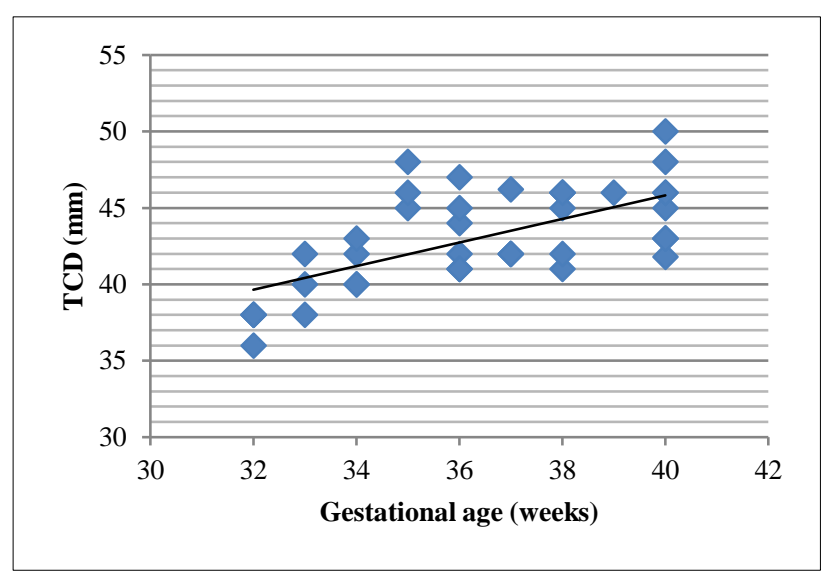

Figure 1: Correlation between TCD and GA in normal growth foetuses.

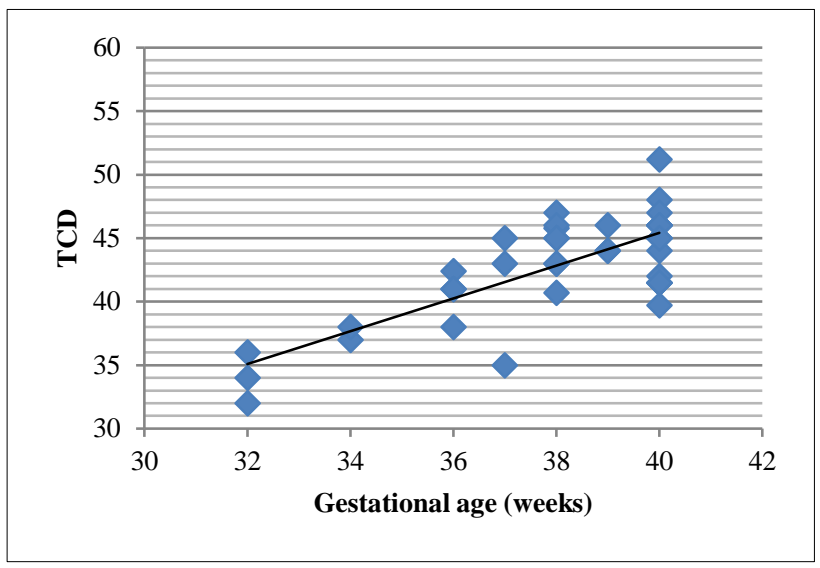

Figure 2: Correlation between TCD and GA in IUGR fetuses

This shows that there is increase in TCD with increasing gestational age in both normal (Figure 1) and IUGR fetuses (Figure 2). The mean TCD was compared between normal and IUGR subjects. The mean TCD showed no significant difference between the two groups when all 40 subjects were analyzed in both groups. When 
TCD was analyzed in different gestational ages of both groups, TCD was not significantly different at most gestational age (Table 2). This non difference in TCD between IUGR and normal fetus showed that TCD is not affected by fetal growth restriction and TCD can be used as predictor of gestational age irrespective of the growth status of fetus.

Table 2: Mean TCD comparison in normal and IUGR new-borns.

\begin{tabular}{|c|c|c|c|c|c|}
\hline \multirow{2}{*}{ Gestational age } & \multicolumn{2}{|c|}{ Normal } & \multicolumn{2}{|c|}{ IUGR } & \multirow{2}{*}{ P value } \\
\hline & $\mathbf{N}$ & Mean \pm SD & $\mathbf{N}$ & Mean \pm SD & \\
\hline 32 weeks & 4 & $37.5 \pm 1$ & 3 & $34 \pm 1.16$ & $0.027 *$ \\
\hline 33 weeks & 3 & $40 \pm 2$ & & & \\
\hline 34 weeks & 4 & $41.25 \pm 1.5$ & 2 & $37.5 \pm 0.71$ & $0.032 *$ \\
\hline 35 weeks & 3 & 46.33 & & & \\
\hline 36 weeks & 6 & $43.33 \pm 2.42$ & 4 & $40.6 \pm 1.86$ & 0.094 \\
\hline 37 weeks & 4 & $43.05 \pm 2.1$ & 3 & $41 \pm 5.29$ & 0.503 \\
\hline 38 weeks & 6 & $44.33 \pm 2.25$ & 8 & $44.44 \pm 2.06$ & 0.930 \\
\hline 39 weeks & 1 & $46 \pm 0$ & 3 & $44.67 \pm 1.16$ & - \\
\hline 40 weeks & 9 & $45.09 \pm 2.70$ & 17 & $44.79 \pm 2.86$ & 0.796 \\
\hline Over all & 40 & $43.1 \pm 3.21$ & 40 & $42.83 \pm 4.10$ & 0.746 \\
\hline
\end{tabular}

\section{DISCUSSION}

Several studies have reported the use of TCD to determine the gestational age. In the present study TCD was studied in normal as well as IUGR fetuses. Contradictory finding has been reported regarding the significance of TCD measurement in fetuses with uncertain GA and fetal growth restrictions. Present study showed that TCD increases linearly with gestational age in both normal and IUGR fetus and there is no significant difference in TCD measurement of normal and IUGR fetuses of same gestational age. Reece and Campbell and similar others studies found no difference in TCD between fetuses of normal and restricted growth, leading to the conclusion that cerebellar growth is unaffected in SGA fetuses and thus might be helpful in predicting gestational age. ${ }^{4,5}$ Lee proposed that TCD measurement can be a reliable predictor of GA in asymmetric growth restriction, but not in symmetric growth restriction. ${ }^{6}$ Vinkesteijin and coworkers did retrospective analysis of 73 growth restricted fetuses and conclude that the TCD is unaffected in IUGR cases. ${ }^{7}$ Chavez and coworker in a prospective analysis reported that TCD measurement was both reliable and accurate in gestational age assessment even in extremes of growth restriction. ${ }^{8}$ TCD is superior to other biometric parameters as it is not affected in many disorders like abnormal skull shapes, fetal growth retardation and multiple pregnancies and large for date fetuses. Goel et al, determined a relationship between gestational ages as an independent predictor of TCD. ${ }^{9}$ luiz et al, in their study found TCD to be more consistent with GA as compared to other biometric parameters. ${ }^{10}$ Uikey et al, and Prasad found BPD and TCD to be better predictors of GA as compared to other fetal biometric parameters. ${ }^{11,12}$
Similar study by Dashottar $\mathrm{S}$ et al. found difference in estimated and actual GA as estimated by TCD were more precise for third trimester $>28$ weeks as compared to 16 to 27 weeks of pregnancy, however, overall estimates strongly correlated with actual gestational age $(r=0.984)$ and thus showed statistically no significant difference between actual and estimated GA thus this study also support that third trimester pregnancy, TCD was a better predictor of GA in pregnancy having combination of both normal as well as IUGR cases. ${ }^{13}$

Similar to present study, the role of TCD in prediction of accurate GA in normal as well as IUGR pregnancy has also been highlighted in several previous studies. ${ }^{14-16}$

Present study also shows there is no significant difference was found in TCD of normal and IUGR fetuses. Hence TCD can be used as independent parameter for GA assessment in third trimester in IUGR cases.

Findings of present study and above-mentioned studies conclude that TCD can be used as independent parameter for GA assessment in third trimester in IUGR fetuses.

\section{CONCLUSION}

Gestational age estimation is an important aspect of antenatal care from both maternal and fetal aspect. Present study showed linear relation between transverse cerebellar diameter and gestational age in both normal and growth retarded fetuses with no difference in TCD of normal and IUGR fetus. TCD may serve as a reliable indicator of gestational age estimation and can be used in cases not sure about LMP and in cases suspicious for IUGR in third trimester. 


\section{ACKNOWLEDGMENTS}

Authors would like to thank department of Pediatrics and Radiology for their support in the study.

Funding: No funding sources

Conflict of interest: None declared

Ethical approval: The study was approved by the Institutional Ethics Committee

\section{REFERENCES}

1. Pinar H, Burke SH, Huang CW, Singer DB, Sung CJ. Reference values for transverse cerebellar diameter throughout gestation. Pediatr Dev Pathol. 2002;5(5):489-94.

2. Mahamoud MZ, Mahamoud OA, Abdulla AA. Fetal transverse cerebellar diameter measurement for prediction of gestational age in pregnant sudanese ladies: Int J Life Sci Med Res. 2013;3I:89-93.

3. Chavez MR, Ananth CV, Smulian JC, Yeo L, Oyelese Y, Vintzileos AM. Fetal transcerebellar diameter measurement with particular emphasis in the third trimester: a reliable predictor of gestational age. Am J Obstet Gynecol. 2004;191:979-84.

4. Reece EA, Goldstein I, Pilu G, Hobbins JC. Fetal cerebellar growth unaffected by intrauterine growth retardation: a new parameter for prenatal diagnosis. Am J Obstet Gynecol. 1987;157:632-8.

5. Gupta AD, Banerjee A, Rammurthy N, Revati P, Jose J, Karak P, et al. Gestational age estimation using trancerebellar diameter with grading of fetal cerebellar growth. National J Clin Ana. 2012;1:11520.

6. Lee W, Barton S, Comstock $\mathrm{CH}$, Bajorek S, Batton D, Kirk JS. Transverse cerebellar diameter: a useful predictor of gestational age for fetuses with asymmetric growth retardation. Am J Obstet Gynecol. 1991;165:1044-50.

7. Vinkesteijn AS, Mulder PG, Wladimiroff JW. Fetal transverse cerebellar diameter measurements in normal and reduced fetal growth. Ultrasound Obstet Gynecol. 2000;15:47-51.

8. Chavez MR, Ananth CV, Kaminsky LM, Smulian JC, Yeo L, Vintzileos AM. Fetal transverse cerebellar diameter measurement for prediction of grstational age in twins. Am Obstet Gynecol. 2006;195:1956-600.
9. Goel P, Singla M, Ghai R, Jain S, Budhiraja V, Rameshbabu CS. Transverse cerebellar diameter - a marker for estimation of gestational age. J Anat Soc India. 2010;59(2):158-61.

10. Luiz N, Fernandes MA, Luiz K. Ultrasonographic evaluation of fetal growth with the use of the transverse cerebellar diameter. Rev Bras Ginecol Obstet. 2000;22(5):281-6.

11. Uikey PA, Kedar KV, Khandale SN. Role of transcerebellar diameter in estimating gestational age in second and third trimester of pregnancy. Int J Repro Contracep Obstet Gynecol. 2016;5(10):3411-5.

12. Prasad BS, Likhitha S. Cerebellar measurements with ultrasonography in the evaluation of fetal age. $\mathrm{J}$ Dent Med Sci. 2014;13(9):49-56.

13. Dashottar S, Senger KPS, Shukla Y, Singh A, Sharma S. Transcerebellar diameter: an effective tool in predicting gestational age in normal and IUGR pregnancy. Int J Reprod Contracept Obstet Gynecol. 2018;7:4190-6.

14. Bansal M, Bansal A, Jain S, Khare S, Ghai R. A study of correlation of transverse cerebellar diameter with gestational age in the normal and growth restricted fetuses in Western Uttar Pradesh. People's J Sci Res. 2014;7(2):16-21.

15. Malik R, Pandya VK, Shrivastava P. Gestational age estimation using transcerebellar diameter with grading of fetal cerebellum and evaluation of TCD/AC (Transcerebellar diameter/abdominal circumference) ratio as a gestational age independent parameter. Indian J Radiol Imaging. 2003;13(1):957.

16. Chavez MR, Ananth CV, Smulian JC, Vintzileas AM. Fetal transcerebellar diameter measurement for prediction of gestational age at the extremes of fetal growth. J Ultrasound Med. 2007;26(9):1167-71.

Cite this article as: Mourya S, Mourya HK, Jain V, Verma M. Fetal transverse cerebellar diameter measurement in intrauterine growth restriction: a more accurate parameter for gestational age assessment at term. Int J Reprod Contracept Obstet Gynecol 2019;8:4391-4. 